\title{
APUNTACIONES CRÍTICAS SOBRE LA HISTORIOGRAFÍA DE LA GULTURA Y DE LA LITERATURA ESPAÑOLAS DEL SIGLO XVIII
}

No cabe duda que el estudio de la literatura española del siglo XVIII, y de otras formas de expresión tales como las artes figurativas y la música, ha adolecido por mucho tiempo de la falta de una atención libre y rigurosa, debido a lo específico de los textos, y a la ausencia de un método interpretativo coherente, capaz de revelar su verdadera naturaleza cultural y que, en la conciencia de lo que es característico en cada uno de ellos, permitiese trazar el complejo y articulado cuadro de sus mutuas relaciones; en otras palabras, que llegase a darnos su historia.

En general, se prefirió sustituir ese estudio atento y consciente por definiciones genéricas y clasificaciones sumarias, la mayoría de las veces basándose en ideas preconcebidas. A mi parecer, el origen del fenómeno se encuentra en haber marginado - separación realizada por el pensamiento ochocentista - lo que fue el más significativo momento cultural del setecientos: la Ilustración. De hecho el romanticismo, en su intento de afirmar la propia autonomía ideológica y cultural, asumió una actitud polémica intransigente ante el pensamiento que le había precedido y de cuyas ideas sin duda se había alimentado. Fue de este modo como se redujo arbitrariamente la Ilustración a un rígido y abstracto racionalismo, carente de sentido histórico, insensible al calor del sentimiento humano e incapaz, por lo tanto, de una verdadera aptitud para la creación artística.

Esta situación estaba lejos de la verdad, precisamente porque el estudio renovado de la historia, el hallazgo de la sensibilidad y el reconocimiento del sentimiento como modalidad fundamental, junto con la razón de la naturaleza humana, provienen de la Ilustración. No obstante, las aludidas creencias pasaron por axiomáticas en toda la crítica romántica y postromántica y se conservaron durante la primera mitad de nuestro siglo. Por lo demás, hasta el día de hoy, a nivel de cultura media, tales conceptos aún sobreviven.

Las consecuencias nocivas de semejante enfoque, más polémico que crítico, se pueden reconocer fácilmente en toda su gravedad. De él derivó la hipótesis de una casi metafísica imposibilidad de coincidencia entre 
la cultura española y la europea del setecientos; lo que se consideraba válido y positivo del siglo XVIII no era tanto lo que - en intercambio fecundo con la civilización europea contemporánea- había sido original e innovador, sino las señales persistentes de una pretendida "tradición" española que servía de puente entre los momentos culturales considerados típicamente hispánicos: el Siglo de Oro y el Romanticismo. De ahí nacía el mito metahistórico del eterno romanticismo español, que caminaba a la par y sin apuros con el otro de la hispanidad, preñado de agobiantes acentos nacionalistas.

De tales presupuestos surgió la difundida tendencia a dedicar escasa consideración - por no decir desprecio- a la cultura del setecientos, especialmente la más innovadora, a la que se etiquetó, de un modo aproximativo y genérico, con el término de neoclasicismo, limitado, más que nada, a la expresión de valores estilístico-formales; término trocado luego, y con frecuencia, por el de afrancesamiento (esta vez con particular referencia a valores ideológico-políticos y con una evidente carga despectiva).

Una consecuencia de ese modo tendencioso y, en el fondo, mistificador, de interpretar la cultura del siglo, es la escasa o casi nula consideración de sus frutos literarios. Lo único que se tomaba en cuenta o se salvaba del naufragio general era lo que aparecía como expresión de la "tradición", continuadora de la edad áurea, o lo que se suponía que era una anticipación del romanticismo.

No se valorizaban ni la cultura implícita en cada texto ni lo específico literario, sino que se intentaba genéricamente reconocer, por medio de algunos textos - con abundantes olvidos y exclusiones calculadas-, una validez ya referida a la cultura y a las formas del pasado, ya a una cultura o formas que más tarde contribuirían a que España tornara al surco de la que se estimaba su característica -y eternadimensión espiritual. Por lo demás, el neoclasicismo era el intento estéril, llevado a cabo por escasos extranjerizantes, de desviar arbitrariamente a España de lo que constituía su esencia.

Bien saben los estudiosos que tal situación de la historiografía sobre el setecientos español duró hasta los años cincuenta cuando, a partir de los estudios de Sarrailh (1954) y de Herr (1958) especialmente, se inició una nueva época ${ }^{1}$.

No obstante, hemos querido apelar preliminarmente a los motivos más remotos que dieron lugar a las incertidumbres, a los equívocos que por tanto tiempo han persistido, pues algunos han echado raíces tan profundas que todavía dan señales de vida, tal vez de un modo inconsciente o bien a causa de la tenaz subsistencia de sugestiones nacionalistas o por la pereza de liberarse de esquemas inveterados y de lugares co-

1 Jean Sarrailh, L'Espagne éclairée de la seconde moitié du xoiii siècle, Paris, 1954 (trad. esp., México, 1957); Richard Herr, The eighteenth-century Revolution in Spain, Princeton, 1958 (trad. esp., Madrid, 1964). 
munes ideológicos. A veces ni siquiera se excluye la tentativa deliberadamente mistificadora, cubierta por un manto de rebuscadas argumentaciones en apariencia convincentes, pero que deforman la realidad histórica.

La obra de Sarrailh tuvo el gran mérito de aclarar, valorizando por primera vez y de modo históricamente apropiado, la influencia del gran movimiento europeo de la Ilustración sobre España ${ }^{2}$, además de establecer, a partir del título de su ensayo más conocido, su colocación exacta en el tiempo. En los últimos treinta años han derivado de este libro numerosos estudios que han contribuido a dar un nuevo perfil a una época reconocida por fin en su propia identidad, especialmente en el plano cultural.

Por lo que concierne a la historiografía literaria, una vez superado el simple y unificador concepto de neoclasicismo, los estudiosos han hallado dificultades en ubicar los nuevos conceptos sobre la cultura de la época -esclarecidos por Sarrailh- en el ámbito de sus clasificaciones habituales con una base estilística y formal. Por otra parte, la falta de carácter unitario de la producción literaria del siglo aparecía bien patente. Debido a estas razones, se llegó a la intrincada subdivisión del siglo en momentos estilísticos reconocidos como barroco, rococó, neoclasicismo y prerromanticismo, a menudo elevados peligrosamente a categoría de época y dedicando escasa atención a lo específico de los textos, a partir de las diversas realidades culturales subyacentes a los mismos. Otro obstáculo era la circunstancia de que el quehacer literario, lejos de avanzar en forma lineal, frecuentemente se presentaba con una abundancia de complejas interferencias y de contradicciones aparentes.

A nuestro parecer, las tentativas de alternar las mencionadas subdivisiones con otros procedimientos tampoco tenían la posibilidad de dar mejores resultados. Me refiero al método de las generaciones, por lo demás discutible en el ámbito de la investigación historiográfica; su empleo llevó a una confusa serie de agrupaciones sostenidas por una sucesión cronológica empírica, que era incapaz de explicar el porqué de ciertas actitudes culturales y de formas expresivas muy divergentes entre sí, en autores pertenecientes a la misma generación ${ }^{3}$.

2 Una aportación notable a la comprensión de la cultura del siglo y en particular de la Ilustración la encontramos en MARIo di Pinto, Cultura spagnola del Settecento, Napoli, 1964 y en los capítulos que este autor dedica al siglo XVII en La letteratura spagnola. Dal Settecento a oggi, Firenze-Milano, 1974. Véanse también las reseñas bibliográficocríticas de conjunto en I. M. ZAVALA, "Hacia un mejor conocimiento del siglo XVIII español", $N R F H, 20$ (1971), 341-360; R. FROLDI, 'L'illuminismo nella cultura spagnola: stato degli studi e prospettive della futura ricerca', en Transactions of the 5th International Congress on the Enlightenment, Oxford, 1980, t. 1, pp. 225-235.

${ }^{3}$ Los ensayos fundamentales que intentan estudiar en la forma aludida las distintas corrientes literarias del siglo XVIII y su periodización son J. ARCE, "Rococó, neoclasicismo y prerromanticismo en la poesía española del siglo xviII', CuCF, 1966, núm. 18, 447-477, y La poesía del siglo ilustrado, Madrid, 1981; José Caso González, J Arce, y J. A. Gaya Nuño, Los conceptos de rococó, neoclasicismo y prerromanticismo en la 
En medio de este esfuerzo por ordenar un material que de repente revelaba significados y estructuras originales, la Ilustración se quedaba atrás; a duras penas se la reconocía como un momento cultural capaz de producir obras de valor literario y poético. Hasta se llegó a reconocer que ciertas obras, evidentemente influidas por el nuevo pensamiento, no eran válidas en sí mismas, sino porque, en potencia, anticipaban el romanticismo. De esta manera se repetían los antiguos errores.

La asimilación parcial del texto de Sarrailh - pues se trata esencialmente de esta situación- se plasmaba en otra tendencia; extender hacia el pasado el concepto de Ilustración y combatir la tesis fundamental de este autor: la asimilación por parte de España de la moderna cultura europea, en particular de la francesa. Se hizo así de la Ilustración un fenómeno de todo el siglo, preparado lentamente en el interior de la misma España, y hasta con ascendencias que se remontaban a los últimos veinte años del siglo XviI.

Es evidente que de este modo se lograba contentar al grupo que se caracterizaba por cierto conservadurismo nacionalista, y que el libro de Sarrailh había ofendido; incluso se podía reivindicar la tesis de los que sostenían el carácter exclusivamente católico de la cultura española. Se llegó hasta a acuñar la fórmula, en contradicción de términos, de "Ilustración cristiana", y se multiplicaron los intentos por definir y caracterizar la Ilustración española insistiendo, sobre todo, en lo que la diferenciaba del pensamiento europeo.

Últimamente se usa con excesiva frecuencia la fórmula "siglo de las luces", modelada del francés "siècle des lumières", aplicada a todo el siglo, sin considerar la enorme diferencia existente entre las dos culturas y sin darse cuenta que, en todo caso, los términos "siglo XVIII" y "luces" no son intercambiables o equivalentes.

Por nuestra parte, estamos convencidos de que la búsqueda de una terminología rigurosamente precisa es condición indispensable para una historiografía que quiera cimentarse sobre bases científicas. Si partimos de la constatación que el término español "Ilustración", correspondiente a "Aufklárung", se usa hoy en sentido historiográfico para definir una realidad cultural que se manifestó en una particular época histórica, con su precisa connotación filosófica y en contacto con específicas manifestaciones literarias y artísticas, estimamos que no se puede dar al término mismo, en relación con la cultura española, un significado diverso del que se aplica a toda la cultura occidental. Esto no quiere decir que la Ilustración española no tenga sus características particulares. Pero el término se justifica por la coincidencia que ofrece, en puntos funda-

literatura española del siglo xviii, Oviedo, 1970. Hay que notar que José Caso GonzÁlez, en su reciente libro, Ilustración y neoclasicismo (t. 4 de la Historia y crítica de la literatura española, Barcelona, 1983), muestra haber abandonado, por "engañoso y equívoco" el término prerromanticismo (p. 16) y renunciado al método de las generaciones. Utiliza todavía el término rococó en sentido estilístico y de poética clasicista. 
mentales, con los procesos culturales afines en el ámbito europeo. Si estas coincidencias no existieran, ni siquiera tendría sentido recurrir al término en cuestión.

En lo referente a la época en que se dio el movimiento ilustrado en España, creemos que Sarrailh acierta cuando identifica la Espagne éclairée con la segunda mitad del siglo XVIII. Es cierto que en los años más recientes el estudio atento que se ha hecho de la cultura de la primera mitad del siglo ha revelado la presencia en ella de síntomas de un despertar (y se ha llegado en esta oportuna obra de investigación incluso hasta los últimos lustros del siglo XVII) que parece contradecir la habitual creencia de una especie de letargo total de España que se prolongaría desde la decadencia del seiscientos hasta principios del siglo XVIII, por lo menos hasta la aparición de las obras de Feijoo.

Para definir este momento cultural no se puede usar el término "Ilustración" como se ha hecho, alejándolo de su significado filosófico e histórico umiversalmente aceptado. Si se usa esta vez en su contenido genérico de "promoción de la luz intelectual contra la ignorancia", acepción que ciertamente existe en español como en otras lenguas, en el campo historiográfico sirve sólo para suscitar confusión y equívoco allí donde no se emplee como verdadero y propio elemento mistificador.

Estudiando las primeras manifestaciones culturales que tienden a salir de la época y de la mentalidad barroca, se tratará de definirlas en forma apropiada según sus características efectivas. Ni siquiera me parece oportuno acogerse al recurso demasiado fácil (experimentado ya, y negativamente) de definir el fenómeno como una proyección anticipada del futuro y, por lo tanto, recurrir a fórmulas tipo "pre-Ilustración" o "primera Ilustración". Es demasiado grande la distancia que separa la verdadera, la auténtica Ilustración de la segunda mitad del siglo, de la cultura de esta primera parte del setecientos.

Hacia finales del siglo XVII e inicios del XVIII, los síntomas esparcidos de una toma de conciencia acerca de la diferencia de nivel cultural entre España y Europa, así como del consiguiente deseo de subsanar carencias a través de la adquisición de un libre espíritu crítico que afirmara la razón contra la autoridad, de hecho se redujeron inicialmente a la iniciativa de pocos nobles, favorecedores de tertulias privadas, de unas cuantas academias públicas y de algunos religiosos que promovieron cautas revisiones filosóficas.

En sustancia, se trató de una rebelión contra el aristotelismo escolástico, hecha en nombre de una actitud experimentalista bastante prudente, la cual no condujo a procesos concretos o resultados reformistas: la realidad española no cambió. De hecho, el poder político (la monarquía de Felipe V y de Fernando VI puede parecer contradictoria; por una parte, se fomentaron instituciones académicas e iniciativas de protección cultural; por la otra, hubo represiones decididas. Sustancialmente, nos parece que se mantuvo bastante coherente en la línea de una defensa sin reservas del conformismo ideológico y en la ostentación de un 
aparato cultural destinado a fines políticos), la Inquisición y, en tales condiciones, la autocensura - naturalmente-, acabaron por impedir todo cambio real ${ }^{4}$.

Después del amplio ensayo de François Lopez ${ }^{5}$, bien documentado y críticamente agudo, se obtiene como dato histórico seguro que gran parte del mérito del incipiente esfuerzo de apertura cultural, a pesar de sus precarios resultados, se debe al grupo valenciano de los novatores (el término, como bien se sabe, se lo aplicaron con ironía despectiva sus adversarios aristotélicos).

El aspecto más significativo de este proceso que desde los primeros novatores se desarrolló en Valencia, sobre todo a través de la obra y el magisterio de Mayans, es la preocupación de combinar el racionalismo crítico de la Europa moderna (no ilustrada todavía) con la gran cultura humanística (y erasmista) del siglo Xvi español, en el intento de activar un retorno de lo que había sido el humanismo cristiano. Esta situación se explica por el consistente interés hacia la temática religiosa, hacia una historiografía sobre todo eclesiástica y hacia un resurgimiento de la filología hebreo-greco-latina. El deán Martí fue maestro de Mayans y entrambos tuvieron como guía ideal sobre todo a Luis Vives.

Mayans fue, sin duda, la figura cultural más significativa de este movimiento de renovación del pensamiento español del quinientos, incluso porque tanto en el campo histórico como en el retórico-filológico se empeñó en afrontar una temática propiamente hispánica y laica, y no sólo clásico-eclesiástica. A pesar de esto, la predicación, el retorno a las fuentes fue constante en él, y cuando programó un plan de reforma educativa lo quiso establecer sobre bases esencialmente teológicas, con una clara actitud de restauración del pasado.

Mayans fue maestro de Cerdá y Rico, de Pérez Bayer, de Piquer, y se debe a Lopez el haber delineado con rigor el filón cultural valenciano que, en el interior de la cultura del setecientos, desde los novatores

4 Es oportuno observar que los autores que se citan como iniciadores de la revisión cultural española a finales del siglo XVil y principios del XVIII o vivieron en el extranjero, razón por la cual tuvieron escasa posibilidad de influir en el ambiente intelectual de la península, o en su patria, en donde encontraron dificultades enormes y hasta tuvieron que renunciar a sus intentos reformadores. Pertenecen al primer grupo Juan Caramuel e Isaac Cardoso Gutiérrez de los Ríos; del segundo se puede recordar que J. Muñoz Peralta y D. M. Zapata sufrieron condenas de la Inquisición, que Juan de Cabriada murió obscuramente en Bilbao, que T.V. Tosca no cosiguió nunca una cátedra universitaria en su Valencia, que Juan de Nájera (el Alejandro de Avendaño de los Diálogos philosóphicos en defensa del atomismo, 1716) retractó sus ideas en los Desengaños filosóficos de 1737. Otros autores evolucionaron hacia ideas que se concillaran con la escolástica (cf. José LUIS ABELLÁN, Historia crítica del pensamiento español, Madrid, 1981, t. 3, pp. 402 s.). En tales condiciones tan sólo pudo desarrollarse una literatura clandestina o popular (véase IRIS M. ZAVALA, Clandestinidady libertinaje erudito en los albores del siglo xuiii, Barcelona, 1978).

5 FrançoIs LoPez, Juan Pablo Forner et la crise de la conscience espagnole au xviii siècle, Bordeaux, 1976, especialmente cap. II. 
ha llegado hasta Forner. Otra cuestión es que este filón deba reconocerse como propiamente "ilustrado". Parece que Lopez lo cree así, y los valencianos Peset y Mestre lo afirman rotundamente 6 . De lo que hemos dicho hasta ahora resulta claro al lector que según nosotros, en lo sustancial, Mayans no atravesó el umbral del pensamiento ilustrado. Demostrar esto con respecto a él y a los que se han considerado, con óptimos argumentos, sus continuadores, sería tarea fácil. Pero no es este el lugar para centrarnos en ese análisis. Tal vez sólo Forner, que, por otra parte, revela con frecuencia su convencida adhesión al humanismo cristiano, se acercó al movimiento ilustrado, especialmente en el campo histórico, aunque no sin contradicciones e incertidumbres.

Volviendo a los autores que caracterizan la cultura española de la primera mitad del setecientos, debemos hacer referencia a Luzán, cuyos intereses dominantes se centran en los campos de la estética y la literatura. Ya en otras ocasiones ${ }^{7}$, he intentado mostrar cuáles fueron las fuentes culturales de Luzán y su participación en el movimiento de renovación, en busca de un acuerdo entre las exigencias del pensamiento racionalista europeo, con el que se familiarizó en su larga estancia en Italia, y una complacida actitud clasicista que, a imitación de Muratori, se apoyaba en los modelos grecolatinos y del quinientos. Con tal bagaje, intentó insertarse en la política cultural, incierta y más que nada académica de Fernando VI. Ciertamente, su Poética tuvo importancia en la España de su tiempo, pero introdujo en este país, en 1737, un pensamiento que pertenecía a la cultura italiana y europea de los primeros años del siglo. Por lo demás, en todas sus manifestaciones literarias, Luzán no penetró nunca en el ámbito de la cultura ilustrada, que sin duda tuvo ocasión de conocer en París, aunque se tratara de un contacto superficial que no dejó huellas en él.

$Y$, en fin, creo que, desde el nivel de la historia de la cultura, es impreciso definir como ilustrado al mismo Feijoo, si queremos respetar con todo rigor y precisión el significado del adjetivo en su dimensión filosófica e histórica, y esto a pesar de que a este autor se le pueda considerar -en un cierto sentido, con honor a la verdad- como el más avanzado de todos en la primera mitad del siglo, sea por la riqueza de sus lecturas de autores modernos (a pesar de que, como con frecuencia se le reprocha, no le llegaban todos de primera mano), sea por la forma

6 MARIANO y José Luis PeSet ReIG, Gregorio Mayans y la reforma universitaria, Valencia, 1975; Vicente PeSet Llorca, Gregori Mayans $i$ la cultura de la Il-lustració, Valencia, 1975; Antonio Mestre, Ilustración y reforma de la Iglesia. Pensamiento político-religioso de don Gregorio Mayans y Siscar, Valencia, 1968; Hestoria, fueros y actitudes políticas. Mayans y la historiografia del siglo xviii, Valencia, 1970; Despotismo e Ilustración en España, Barcelona, 1976; y El mundo intelectual de Mayans, Valencia, 1978.

7 R. FROLDI, "Significación de Luzán en la cultura y literatura española del siglo XVIII", $C H(6)$, pp. 285-289, y “El último Luzán”, en La época de Fernando VI, Oviedo, 1981, pp. 353-366. 
comunicativa de su pensamiento (Cartas y Discursos que se acercan a ensayos) o, finalmente, por el gran séquito de lectores que tuvo.

Sostenedor de un empirismo prudente, se proclamó paladín de la ciencia contra la ignorancia y la superstición popular, aunque, quizá por su condición de fraile, siempre guardó respeto por la fe y sus justificaciones metafísicas, sin llegar nunca - con rechazo del empeño de definirla sistemáticamente - a una aceptación de la ciencia en su valor propio, como tampoco a un nuevo concepto de la naturaleza.

Por lo que a Feijoo se refiere, compartimos el parecer de Abellán quien, a pesar de reconocer sus méritos y su importancia de divulgador genial de la renovación, siente el deber de precisar que, a pesar de todo, no osó "dar el salto a la Ilustración" 8 .

En la España de la segunda mitad del setecientos se advierte con claridad la llegada de una realidad cultural decididamente nueva. Su realización se debe a un grupo de aristócratas, juristas, políticos y literatos, favorecidos en gran parte por la política de Carlos III. Se trató de un verdadero intento de ilustración, alimentado por un decidido repudio al pasado y un neto acercamiento a posiciones europeas contemporáneas.

Me resulta difícil coincidir con quienes proponen una visión unitaria del siglo, en la segunda parte del cual se recogieron los frutos nacidos y cuidados en la primera. Es verdad que se registran elementos de continuidad, como, por lo demás, siempre ocurre en la historia; pero en el caso del siglo XVIII español, nos parece que en su segunda mitad prevalecen los motivos de cambio y, con frecuencia, de una verdadera ruptura.

El proceso innovador que caracteriza este período consistió en el claro intento de introducir en la cultura española una serie de elementos modificadores, de un modo profundo y en muchos casos radical. Los modelos son los del pensamiento contemporáneo, ilustrado y enciclopedista, del que se piensa que puede reincorporar rápidamente a España en las formas de la cultura que se consideran universales. Las propuestas innovadoras no provienen de los eclesiásticos sino de los laicos, es decir, de algún representante de la aristocracia o de la burocracia estatal. Su acogida se da en los pequeños grupos burgueses existentes - en ciudades periféricas sobre todo-, ocupados en traficar y que, por lo tanto, tenían más contacto con extranjeros. El fenómeno alcanza todos los campos del saber y de la actividad práctica.

En el campo filosófico se advierte el creciente influjo del pensamiento sensista; cada vez se marginan más las investigaciones de tipo metafísico y teológico, lo que da lugar a una verdadera inversión en la relación tradicional entre trascendencia e inmanencia. Cambia también el concepto de naturaleza, en el que se incluye al hombre que quiere conocerse a fondo en su compleja realidad. La ciencia pasa de la experimentación racionalista a una aceptación decidida del experimentalismo sensista,

8 ABELLÁN, op. cit., p. 503. 
y se impone como equivalente de la filosofía. Incluso el hombre es objeto de este tipo de investigación, mientras que la felicidad aparece como nueva finalidad existencial a la que se llega por medio de una mejor organización social y del desarrollo técnico, guiados por el concepto de utilidad.

Deriva de este cambio de mentalidad - sintetizada por Kant en la fórmula del sapere aude - la crisis de la enseñanza religiosa tradicional. Se buscan nuevas ideas pedagógicas, se programan - aunque sólo en parte se realicen- las reformas de los colegios y de la universidad. La expulsión de los jesuitas en 1767 (claramente originada por razones políticas que convencen a Carlos III a superar su fuerte pietismo a favor del absolutismo y el regalismo) ayudará al esfuerzo reformista. El concepto de la necesidad de difundir la cultura, y de una instrucción básica y extendida, suplanta el academicismo elitista que caracterizó los reinados de Felipe $\mathrm{V}$ y Fernando VI ${ }^{9}$.

Por otra parte, el mismo pensamiento religioso, en sus mejores exponentes, advertirá la necesidad de revisar las propias posiciones doctrinales. Tal fue el caso de los religiosos a los que se definió como jansenistas, con base en las acusaciones que los jesuitas les habían lanzado, y a pesar de que fundamentaron su doctrina más en la tradición del humanismo cristiano que en las auténticas tesis de Cornelio Jansen. Hasta cierto punto, ellos se encontraron cercanos al regalismo a causa de su repudio por la Inquisición - que se mantuvo jesuítica incluso después de la expulsión de los jesuitas-, y hasta el monarca los protegió en algunas de sus aspiraciones jurisdiccionales. Precisamente este acercamiento al despotismo ilustrado, así como su fuerte aspiración a una mayor autonomía y libertad de conciencia, expresión de una sentida e íntima religiosidad, dieron lugar para hablar de "Ilustración cristiana". Mas, en realidad, se trató de un movimiento reformista que jamás aceptó, ni podía aceptar, los aspectos más innovadores de la Ilustración, ya que el movimiento era al mismo tiempo, "le fils et l'adversaire de son siècle", según la acertada afirmación de Saugnieux ${ }^{10}$, aunque sirviera de sostén al reformismo borbónico.

Otro aspecto innovador, relacionado con los mudados conceptos de "hombre" y "sociedad", y con la afirmación decidida del ideal utilitarista, es el desarrollo de los estudios de economía política y la búsqueda concreta de reformas económicas. Todo ello se incluye en la finalidad de alcanzar la felicidad a la que aludíamos anteriormente; ideal estrechamente unido a la voluntad de afirmación de la plena libertad del hombre ${ }^{11}$.

9 Sobre la cultura bajo Fernando VI, véase F. Aguilar Piñal, "La cultura en el reinado de Fernando VI', en La época de Fernando VI, ed. cit., pp. 297-313, y Bibliografía de autores españoles del siglo xviii, Madrid, 1981-84, 3 ts.

10 JoËL SaugnieuX, Le jansénisme espagnol du xviïi siècle, ses composantes et ses sources, Oviedo, 1975, p. 10.

11 Además de los conocidos estudios de P. Vilar, A. Domínguez Ortiz y G. 
En el campo del pensamiento ilustrado, se comprende cómo el desarrollo lógico del pensamiento político desemboca en la afirmación de los derechos del ciudadano - ya no súbdito- contra la monarquía absoluta. Con otras palabras: se asiste a una como apertura del camino hacia principios constitucionales o incluso hacia más radicales posturas democráticas. Maravall y Elorza ${ }^{12}$ nos hacen ver con claridad cómo la Ilustración conducía al liberalismo económico y político en el pensamiento de hombres que iban mucho más allá del llamado "despotismo ilustrado": Ibáñez de la Rentería, Cabarrús, León de Arroyal y el grupo salmantino, que Beneyto ${ }^{13}$ define como "escuela iluminista salmantina".

Esta situación nos debe hacer reflexionar sobre la necesidad de no reducir la Ilustración, fenómeno tan rico y complejo, al simple aspecto, al momento político del despotismo ilustrado. De hecho, este fenómeno está ligado a una larga tradición del absolutismo monárquico que sólo con Carlos III acepta directrices claramente ilustradas, para entendernos, de tipo josefino. Sin embargo, permanece siempre un absolutismo que se contrapone a las nacientes ansias de libertad. Por este motivo, se puede hablar de una verdadera oposición (aunque, con prevalencia, sólo a nivel ideológico) bajo Carlos III y luego bajo Carlos IV, ya en el camino del constitucionalismo que llevará hacia las Cortes de Cádiz.

Entre la primera y la segunda parte del siglo, se da un cambio decidido incluso en el campo de la estética y de la literatura ${ }^{14}$. Si Luzán y el pensamiento racionalista contribuyeron a alejar las teorías y la práctica barrocas, introduciendo un clasicismo modelado sobre cánones y ejemplos grecolatinos y españoles del quinientos, en la segunda mitad del siglo los modelos son, con frecuencia, los modernos, sobre todo fran-

ANES, son fundamentales, en el plano sociológico, los trabajos de J.A. Maravall, "La idea de felicidad en el programa de la Ilustración" en Mélanges offerts à Charles Vicent Aubrun, Paris, 1975, t. 1. pp. 425-462, y "Espíritu burgués y principio de interés personal en la Ilustración española", $H R, 47$ (1979), 291-325.

$12 \mathrm{~J}$. A. Maravall, "Las tendencias de reforma política en el siglo XVIII", ROcc, 18 (1967), 53-82; ANTONIO Elorza, La ideología liberal en la Ilustración española, Madrid, 1970.

13 Juan Beneyto Pérez, La escuela iluminista salmantina, Salamanca, 1949.

14 Han publicado estudios de conjunto sobre la literatura española del siglo xvinI, además de Mario di Pinto (cf., supra nota 2), Nigel GLendinning, A literary history of Spain: the eighteenth century, London, 1972 (trad. esp. 1973); JUAN LUIS AlbORG, Historia de la literatura española, siglo xviii, Madrid, 1972; RENÉ ANDIOC, J. ARCE, J. CASO González, E. Catena, Historia de la literatura española, ed. J.M. Díez Borque, Madrid, 1975, t. 2 (reed. Madrid, 1980); Francisco Aguilar Piñal, E. Catena, A. LAbandeira Fernández y E. Palacios Fernández, Historia de la literatura española e hispanoamericana, Madrid, 1980. Iris M. Zavala ha trazado un perfil del siglo XVIII (CARlos Blanco Aguinaga, J. Rodríguez Puértolas, e I.M. Zavala, Historia social de la literatura [en lengua castellana], Madrid, 1978, t. 2); y Caso González, además del ya citado tomo de la Historiary crítica de la literatura española, en el que indica lo que falta por hacer en la investigación del siglo XVIII, es autor de dos capítulos sobre la literatura española del setecientos en los ts. 29 y 31 (en prensa) de la Historia de España iniciada por Menéndez Pidal. 
ceses. Al debilitarse el rigorismo normativo de Luzán, persiste una difundida necesidad de orden, equilibrio y decoro, de herencia clásico-humanista. Pero con el cambio de los contenidos se van modificando también las formas.

A través del examen nuevo de la naturaleza y del hombre, bajo la guía del pensamiento sensista, la estética ilustrada presta atención sobre todo a los aspectos sicológicos que produce la obra de arte. Se persigue el equilibrio entre entendimiento y sensibilidad y se añaden al arte funciones educadoras, buscando lo que es socialmente útil, a través de un estímulo de los impulsos afectivos y siempre bajo el control de la razón. Nace de esto una literatura muy variada y compleja, a menudo experimental. Pero sería un error pensar que dicha actitud constituye un límite y no prestar atención a la originalidad de sus manifestaciones. La actitud de haber querido adosar a la literatura del período que estamos examinando (siguiendo las huellas de Van Thieghem y de sus seguidores) la etiqueta de "prerromanticismo" -tomando como base una identificación simplista entre sentimiento y romanticismo- ha sido sólo fuente de equívocos.

El romanticismo, que tendrá un concepto profundamente distinto tanto del "yo" como de la naturaleza, dará un valor absoluto al sentimiento, viniendo a romper así el buscado y realizado equilibrio de los autores ilustrados.

No es este el lugar para que nos detengamos en un análisis de la multiplicidad de las manifestaciones literarias españolas de la segunda mitad del setecientos. Baste subrayar que en esta época nace una nueva poesía que no es ilustrada solamente cuando afronta ciertos grandes temas filosóficos, políticos o humanitarios, o cuando se centra en finalidades didascálicas; es ilustrada también cuando al afrontar, bajo formas idílicas o anacreónticas, temas de la naturaleza, reelabora en formas nuevas los modelos antiguos, inevitablemente presentes, en contacto con un nuevo contenido ideológico y moral. Se ha estudiado demasiado poco el aspecto de la originalidad de estos textos ilustrados con respecto a la tradición. No creemos que el problema se resuelva poniendo a éstos, $\mathrm{u}$ otros afines, la etiqueta de rococó. Para nosotros, este término, en contexto historiográfico, es insuficiente si con él se quiere expresar un estilo de época o sólo una modalidad estilística de la Ilustración literaria. Esto no quiere decir que en la España de la época no se difundiera un gusto rococó, es decir, una sensibilidad influida por ciertas formas de las artes visuales. De todos modos, nos parece que se trata de un componente accesorio del gusto que no puede elevarse a categoría histórica.

Es oportuno recordar también la gran importancia que asume la prosa científica con una realidad formal tal vez anónima o de grupo (pensemos en el desarrollo de la prensa periódica, que se abre paso entre muchas dificultades de censura) en múltiples campos: historia, filosofía, política, economía, derecho, crítica literaria, para no hablar de las 
primeras aproximaciones a la antropología, a la sociología y a la lingüística, y a la prosa técnico-científica en sentido estricto; todo ello bajo la guía de una clara voluntad de innovación y con un fondo patriótico. Así, se impone el ideal de "cultivar la nación" con el fin de realizar lo antes posible una serie de progresos civiles bien concretos, a modo de lo que en Italia Genovesi supo sintetizar en la fórmula "cose, non parole".

Esta perspectiva de innovación también atañe al teatro. Se dejará a un lado la arqueología formal de Montiano, para suplantarla por el esfuerzo de crear una tragedia que respondiera a las exigencias precisas del momento, o bien una comedia, de Iriarte a Moratín, que fuese instrumento de regeneración ideológica y moral. A conclusiones parecidas creo que podría llegar un estudio exhaustivo de la narrativa de la época (textos originales y traducciones), estudio que todavía falta.

Así es que en la segunda parte del siglo encontramos un preciso sistema de ideas y valores bien estructurados (la "estructura de pensamiento" de la que habla Maravall), que nos induce a pensar en el concepto de Ilustración como concepto de época, aunque en España se delimite bien en su naturaleza ideológica y su realidad político-social, además de su reducido espacio temporal. Tal concepto ya no sería evidente si, de un modo arbitrario, se extendiera a momentos históricos caracterizados por mentalidades diversas.

Por otra parte, hay que tener presente que estas diversas mentalidades coexisten con la Ilustración, la cual (no hay que olvidarlo) se realizó como obra de una minoría reducida, aunque eficiente y capaz de determinar la adquisición de valores que entrarían a formar parte de la cultura española, a pesar de la interrupción del proceso innovador bajo Carlos IV y Fernando VII.

De hecho, al mismo tiempo que se desarrollaba la cultura ilustrada, encontramos los epígonos de los novatores y de Mayans, no lejanos por su actitud de fondo del grupo de los católicos reformistas, impropiamente llamados jansenistas, influidos por la Ilustración en lo que respecta a su proceso de revisión y actualización, pero que no pueden confundirse tout court con los ilustrados. Es oportuno mencionar también a los jesuitas expulsados que, en Italia, renovaron su bagaje cultural y supieron producir notables frutos en varios campos culturales, pero que siempre se mantuvieron fuera de la Ilustración verdadera, o a lo más, intentaron doblegar algunos elementos del pensamiento ilustrado en defensa de su patrimonio espiritual ${ }^{15}$.

Por último, entre los contemporáneos de los ilustrados, recordemos a los conservadores de ideales del pasado, como García de La Huerta, o a los pensadores más retrógrados y reaccionarios, estudiados por

15 Hubo excepciones como la de Pedro Montengón, que dejó la Compañía; véase M. FABBRI, Un aspetto dell'Illuminismo spagnolo: l'opera letteraria di Pedro Montengón, Pisa, 1972 . 
Herrero ${ }^{16}$. A estos últimos no hay que quitarles importancia histórica, pues fueron ellos - en concomitancia con el difícil período de la Revolución francesa, en el reinado de Carlos IV y de la llamada Guerra de la Independencia- quienes primero frenaron, para callarlo después, el gran movimiento ilustrado, restaurando la estrecha alianza entre trono y altar. Si el privilegio aristocrático y eclesiástico acabó por triunfar mediante la dura restauración de Fernando VII, esto sin duda se debe a una serie de factores, entre los cuales emerge la ausencia en España de una burguesía fuerte, capaz de hacer salir a la Ilustración de los límites de la iniciativa de una minoría.

En el campo literario, la inversión de tendencia se puso de manifiesto en el primer romanticismo, claramente politiquero y reaccionario, y condujo al sacrificio o al reajuste de los valores más específicamente ideológicos y reformadores de la Ilustración, a favor de un marcado formalismo y retoricismo, que - en definitiva- es lo que con más propiedad se podría llamar neoclasicismo.

Todo esto no menoscaba a la Ilustración, que se identifica con una ruptura decidida con un pasado decadente, enlace con la cultura moderna europea y, de ahí, un efectivo inicio de la España moderna. La ominosa década sólo pudo bloquearla temporalmente, pero luego maduró la simiente echada. Tanto en el ochocientos como en nuestro siglo, se nutrieron de la Ilustración todos los movimientos que sucesivamente quisieron hacer de España un país de cultura moderna y universal.

En estos apuntes, lo que más nos interesa subrayar es que sólo partiendo de ideas claras sobre la multiforme cultura del siglo XviIr se puede tener la posibilidad de comprender los textos de la época, incluso en su valor más específicamente literario. Si nos atenemos a esta idea, considero que se impone a la historiografía la necesidad de no dejarse condicionar por la convencionalidad del ámbito cronológico secular y de tener la valentía de reconocer la fundamental diversidad que existe en la cultura de la primera y la segunda parte del siglo. La renovación racionalista no se puede confundir con la innovación ilustrada en una indistinta continuidad cultural.

España no ha tenido un completo "siglo de las luces", sino solamente una época (a partir de 1760 hasta los primeros años del siglo XIX) que se puede definir legítimamente como Ilustración. Por lo demás, si - observamos bien, la España moderna tiene vínculos con el momento cultural de la Ilustración y no con la de la primera mitad del siglo. Ciertamente no daña a la Ilustración el que se la redujera a un limitado espacio ideológico y cronológico. Creemos que la labor de los futuros estudiosos habrá de ser la de precisar cada vez mejor, dentro de los límites reconocidos, los caracteres del fenómeno.

Por nuestra parte, nos hemos preocupado en establecer la correspondencia entre la realidad histórica y la terminología con que se in-

16 Javier Herrero, Los orígenes del pensamiento reaccionario español, Madrid, 1971. 
tenta explicarla. Pensamos que restringir un concepto a lo que sólo le es propio es una condición esencial para la claridad del concepto mismo ${ }^{17}$ y corresponde a lo que, desde siempre, es la verdadera labor de la crítica: entender y hacer entender.

Universidad de Bolonia.

RinaLdo Froldi

17 De acuerdo con esta necesidad metodológica fundamental, consideramos impropio e historiográficamente peligroso extender y fechar con anticipación el concepto de romanticismo como hace Russell P. SEBOld en Colonel don José Cadalso, New York, 1971 (trad. esp., Cadalso: el primer romántico "europeo" de España, Madrid, 1974), y Trayectoria del romanticismo español, Barcelona, 1983. De este modo otra vez la literatura de la Ilustración corre el riesgo de no ser juzgada en sí misma. 